\title{
Micromorphology of antral follicles in cattle after prostaglandin-induced luteolysis, with particular reference to atypical granulosa cells
}

\author{
R. van den Hurk ${ }^{1}$, G. Dijkstra ${ }^{1}$, S. C. J. Hulshof ${ }^{1}$ and \\ P. L. A. M. $\operatorname{Vos}^{2}$ \\ ${ }^{1}$ Department of Functional Morphology, Faculty of Veterinary Medicine, University of Utrecht, \\ Yalelaan 1, 3508 TD Utrecht, Netherlands; and ${ }^{2}$ Department of Herd Health and Reproduction, \\ Faculty of Veterinary Medicine, University of Utrecht, Yalelaan 7, Utrecht, Netherlands
}

\begin{abstract}
Dutch Friesian heifers $(n=13)$ and cows $(n=13)$ were used to obtain information about the number, size and micromorphology of antral follicles ( $\geq 3 \mathrm{~mm}$ in diameter) in cattle after induction of luteolysis with the $\mathrm{PGF}_{2 \alpha}$ analogue luprostiol. Special attention was paid to the presence of atypical granulosa cells in these follicles to obtain additional data to help evaluate the hypothesis that these cells are markers of follicular atresia. Animals were injected i.m. with $15 \mathrm{mg}$ of the synthetic prostaglandin on day 10 or day 11 of the oestrous cycle. The ovaries were collected on day 12, that is 48 and $24 \mathrm{~h}$ after injection of luprostiol, respectively. After prostaglandin-induced luteolysis, the mean number of medium-sized and large nonatretic follicles and of medium-sized atretic follicles had not changed in heifers and in cows, compared with those of untreated animals. However, in heifers, contrary to cows, the development of a preovulatory-sized follicle was initially accompanied by an increase in the number of large definitely atretic follicles. Atypical granulosa cells can be considered as markers for a lower quality follicle, on the basis of their absence in preovulatory-sized follicles and their presence in large numbers in a high proportion of definitely atretic follicles. If it is assumed that only a nonatretic follicle without atypical granulosa cells will grow to preovulatory size, growth of this follicle within 2 days after prostaglandin treatment was almost $9 \mathrm{~mm}$ and over $10 \mathrm{~mm}$ in heifers and cows, respectively. In cows, most growth of follicles was observed at the first day after prostaglandin treatment; in heifers, this occurred one day later.
\end{abstract}

\section{Introduction}

Prostaglandins are formed in many tissues and have various functions (Walpole, 1975). In cattle, prostaglandins from the uterus evoke regression of the corpus luteum, which leads to reduced progesterone concentrations, followed by the development of a preovulatory follicle, the start of a preovulatory LH surge and eventually ovulation (Louis et al., 1975; Hansel and Convey, 1983). Endogenous prostaglandins are cleared rapidly from the circulation (Walpole, 1975). More stable prostaglandin analogues, such as cloprostenol (Estrumate: ICI, Macclesfield) and luprostiol (Prosolvin: Intervet, Boxmeer), are commonly used for their luteolytic action or for synchronization of oestrus and ovulation (Wright and Malmo, 1992). Although the luteolytic effect of these exogenous prostaglandins has been well documented (Hansel and Convey, 1983), little information is available on the micromorphology of the population of bovine antral follicles after luteolysis induced by prostaglandin analogues (Ireland and Roche, 1982).
Prostaglandins are often given in combination with pregnant mares' serum gonadotrophin (PMSG) to evoke a superovulation response in farm animals (Phillipo and Rowson, 1975; Dieleman and Bevers, 1987; Gallo et al., 1992). We recently reported the effects of PMSG on the number and the micromorphology of antral follicles in heifers (van den Hurk et al., 1992; van den Hurk and Dijkstra, 1992). In these studies, atypical granulosa cells could be morphologically distinguished from normal granulosa cells. On the basis of ultrastructural findings, we hypothesized that the presence of atypical granulosa cells in follicles hitherto called nonatretic was associated with the onset of follicular atresia. Information on the possible involvement of atypical granulosa cells in follicular atresia can be extended by more detailed studies on the occurrence of these cells in atretic and nonatretic follicles, including the preovulatory-sized ones that develop after prostaglandininduced luteolysis.

The present study on bovine antral follicles was carried out to obtain more information about micromorphology, number and size of these follicles after luteolysis induced by the PGF $2 \alpha$ analogue luprostiol. In this respect, special attention was paid 
to the presence of atypical granulosa cells in antral follicles to obtain more information to assess the hypothesis that these cells are markers of follicular atresia.

\section{Materials and Methods}

\section{Animals}

Experiments were carried out from October to December 1991 with Dutch Friesian heifers $(n=13 ; 450-500 \mathrm{~kg})$ and cows $(n=13 ; 600-750 \mathrm{~kg})$. Housing and detection of oestrus were as described by Dieleman et al. (1983). The time when animals allowed mounting on at least two consecutive occasions was regarded as the onset of oestrus and the day on which this occurred was defined as day 0 . Luteal function was assessed by determination of the progesterone concentration in the peripheral blood according to the method described by Dieleman and Bevers (1987). Animals used in these studies had 8-10 nmol progesterone $\mathrm{I}^{-1}$ in the peripheral blood on day 10 (that is, during the midluteal stage) of the oestrous cycle. At day 10, three heifers (14-16 months of age) and three cows (4-6 years of age) were injected with $15 \mathrm{mg}$ of the prostaglandin analogue, luprostiol (Prosolvin: Intervet), whereas another five heifers and five cows were injected at day 11 with the same compound. All ovaries were collected by ovariectomy at day 12 , i.e. $48 \mathrm{~h}$ or $24 \mathrm{~h}$ after prostaglandin treatment, respectively. Ovaries obtained from five untreated heifers and five untreated cows on day 12 of the oestrous cycle served as controls. Previous studies (P. L. A. M. Vos, unpublished) showed that oestrus occurs 3 days after prostaglandin injection at the midluteal phase of cows.

\section{Histology}

Ovaries from heifers were fixed in Bouin's fluid, dehydrated in a graded series of ethanol and embedded in paraffin wax. These ovaries were sectioned on a microtome. From cow ovaries, all follicles $\geq 3 \mathrm{~mm}$ were excised, measured and then processed for routine histological examination as described above. Serial sections, $5 \mu \mathrm{m}$ thick, were stained with periodic acid-Schiff-haematoxylin. All antral follicles $\geq 3 \mathrm{~mm}$ were counted and micromorphologically evaluated, following criteria described by van den Hurk et al. (1992). In addition, the number of atypical granulosa cells was established in at least three cross-sections through each follicle, including the largest cross-section; the number of atypical granulosa cells per cross-section in nonatretic and atretic follicles was compared. Antral follicles were allocated to two size categories according to diameter $(3-5.9 \mathrm{~mm}$ and $\geq 6 \mathrm{~mm})$. The diameter of each follicle was calculated according to Choudary et al. (1968). Values were corrected for $10 \%$ shrinkage according to Kruip and Dieleman (1982). In each size category, mean numbers of a specific type of follicle were calculated; the data for treated and untreated animals were then compared.

\section{Statistical analysis}

The $\chi^{2}$ test for $k$ independent samples (Siegel, 1959) was applied to compare the numbers of atypical granulosa cells in nonatretic, lightly atretic and definitely atretic follicles $\geq 3 \mathrm{~mm}$. The nonparametric Kruskal-Wallis one-way ANOVA followed by the Mann-Whitney $U$ test (Siegel, 1959) were used to compare data on the number of nonatretic and atretic follicles in corresponding size categories. The level of statistical significance was set at $P<0.05$.

\section{Results}

Atypical granulosa cells, characterized by their elongated shape and oblong nucleus were found in nonatretic, lightly atretic and definitely atretic follicles (Fig. 1a-c) both in untreated and prostaglandin-treated animals. In nonatretic and lightly atretic follicles atypical granulosa cells were found in the basal area of the granulosa. In definitely atretic follicles, they were also found in more apical regions. In heavily atretic follicles, the granulosa had reduced to a single layer or few layers of cells in which atypical granulosa cells were absent (Fig. Id). The numbers and percentages of nonatretic, lightly atretic and definitely atretic follicles $\geq 3 \mathrm{~mm}$ without $(0)$, with small (1-5), with moderate (6-50) and with large $(>50)$ numbers of atypical granulosa cells per cross-section through a particular follicle are given (Table 1). Data from untreated and treated heifers and cows are combined. The results show that the proportion of follicles with large numbers of atypical granulosa cells is higher in the category of definitely atretic follicles than in nonatretic follicles $(P<0.01)$, and follicles in the lightly atretic category were intermediate.

Neither the mean number of medium-sized $(3.0-5.9 \mathrm{~mm})$ antral (nonatretic plus atretic) follicles nor that of large $(\geq 6 \mathrm{~mm}$ ) antral follicles in prostaglandin-treated heifers (Table 2) and cows (Table 3) was significantly different from that of untreated animals. In heifers, however, the mean number of medium-sized nonatretic follicles was significantly enhanced at $24 \mathrm{~h}$ after prostaglandin treatment, when compared with those at $48 \mathrm{~h}$ (Table 2). This was due to the development of at least one medium-sized nonatretic follicle without atypical granulosa cells in each heifer. These latter medium-sized follicles were absent in both heifers and cows at $48 \mathrm{~h}$ after prostaglandin treatment; however, all of these animals had one large nonatretic (preovulatory-sized) follicle that lacked atypical granulosa cells (Fig. 1e). The mean numbers of medium-sized atretic (lightly atretic plus definitely atretic plus heavily atretic) follicles in prostaglandin-treated heifers (Table 2) and cows (Table 3) was not significantly different from that of the corresponding control animals. When atretic follicles were subdivided, on the basis of the extent of atresia, prostaglandininduced luteolysis had not influenced the mean number of medium-sized lightly atretic, definitely atretic or heavily atretic follicles in both heifers and cows. This was also the case for the large atretic follicles of cows. In heifers, however, the mean number of large atretic follicles had increased at $24 \mathrm{~h}$ after prostaglandin treatment, owing to increased numbers of definitely atretic follicles. At $48 \mathrm{~h}$ after prostaglandin treatment, these values had returned to control values.

The mean size of the largest antral follicle (either nonatretic or atretic), the largest atretic follicle, the largest nonatretic follicle (either with or without atypical granulosa cells) and the largest nonatretic follicle without atypical granulosa cells in the ovaries of untreated and prostaglandin-treated animals are 

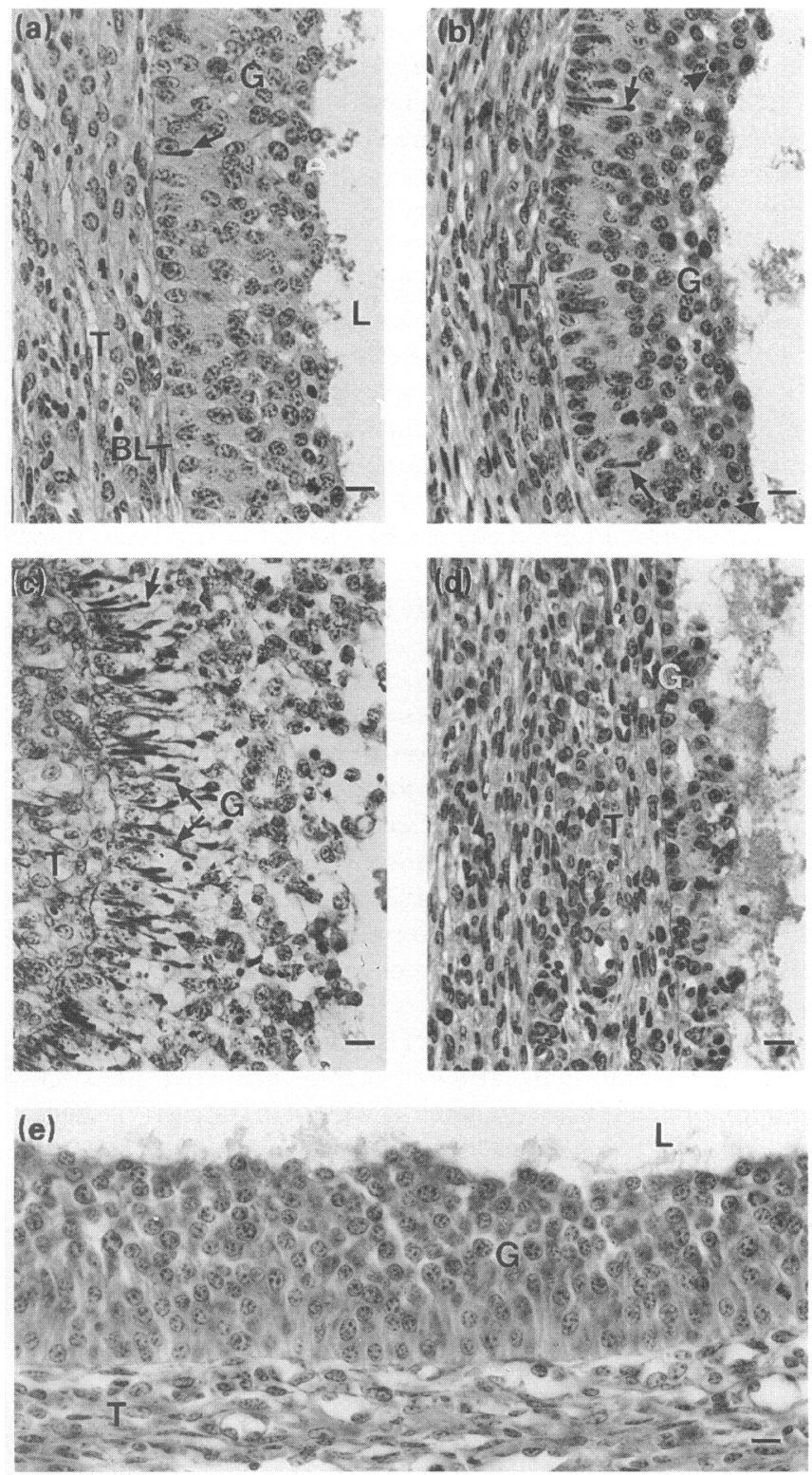

Fig. 1. Photomicrographs of sections of antral follicles. Periodic acidSchiffs (PAS)-haematoxylin. Part of (a) a nonatretic follicle with an atypical granulosa cell (arrow), (b) a lightly atretic follicle with a few atypical granulosa cells (arrows) and pyknotic nuclei (arrowheads), (c) a definitely atretic follicle with numerous atypical granulosa cells (arrows) and pyknotic nuclei, (d) a heavily atretic follicle, and (e) a preovulatory-sized follicle. Note the absence of atypical granulosa cells. Bars represent $10 \mu \mathrm{m}$. G: granulosa; T: theca interna; L: follicular lumen; BL: basal lamina.

shown (Table 4). The mean size of the largest antral follicle did not change after prostaglandin treatment. The mean size of nonatretic follicles, on the contrary, was enhanced and was 6.5 and $8.4 \mathrm{~mm}$ within 2 days after prostaglandin treatment in heifers and cows, respectively. In this period, the mean size of the largest atretic follicle decreased 3.2 and $9.3 \mathrm{~mm}$ in heifers and cows, respectively. The mean diameter of nonatretic follicles without atypical granulosa cells was 8.7 and $10.4 \mathrm{~mm}$ larger in heifers and cows, respectively, at $48 \mathrm{~h}$ after PG
Table 1. Numbers and percentages (\%) of nonatretic, lightly atretic and definitely atretic follicles $\geq 3 \mathrm{~mm}$ with $0,1-5,6-50$ or $>50$ atypical granulosa cells per cross-section in cattle $(n=26)$

\begin{tabular}{lcccc}
\hline $\begin{array}{l}\text { Number of atypical } \\
\text { granulosa cells }\end{array}$ & $\begin{array}{c}\text { Nonatretic } \\
(\%)\end{array}$ & $\begin{array}{c}\text { Follicle category } \\
\text { Lightly-atretic } \\
(\%)\end{array}$ & $\begin{array}{c}\text { Definitely-atretic } \\
(\%)\end{array}$ \\
\hline 0 & $24(40.0)$ & $5(5.0)$ & $0(0.0)$ \\
$1-5$ & $18(30.0)$ & $15(14.9)$ & $8(7.4)$ \\
$6-50$ & $18(30.0)$ & $60(59.4)$ & $52(47.7)$ \\
$>50$ & $0(0.0)$ & $21(20.7)$ & $49(44.9)$ \\
\hline
\end{tabular}

Table 2. The effect of the prostaglandin analogue luprostiol $(\mathrm{PG})$ at $24 \mathrm{~h}$ and $48 \mathrm{~h}$ after injection on the mean number $( \pm$ SEM) of medium-sized $(3.0-5.9 \mathrm{~mm})$ and large $(\geq 6 \mathrm{~mm})$ ovarian follicles in heifers

\begin{tabular}{llll}
\hline & \multicolumn{3}{c}{ Heifers } \\
\cline { 2 - 4 } Follicles & Untreated & PG 24 h & PG 48 h \\
\hline Antral (3-5.9 mm) & $9.4(3.3)$ & $10.0(1.5)$ & $8.7(3.9)$ \\
Nonatretic & $1.8(1.0)$ & $2.6(1.5)^{\mathrm{b}}$ & $0.0(0.0)$ \\
NA - AGCs & $0.2(0.2)$ & $1.2(0.2)^{\mathrm{b}}$ & $0.0(0.0)$ \\
NA + AGCs & $1.4(0.9)$ & $1.4(0.5)$ & $0.0(0.0)$ \\
Atretic & $7.6(3.6)$ & $7.4(1.4)$ & $8.7(3.9)$ \\
LA & $3.2(2.7)$ & $2.4(0.9)$ & $2.3(1.8)$ \\
DA & $1.2(0.7)$ & $2.8(0.8)$ & $4.0(1.5)$ \\
HA & $3.2(1.2)$ & $2.2(0.7)$ & $2.3(0.7)$ \\
Antral ( $\geq 0$ mm) & $3.0(1.0)$ & $8.0(1.8)$ & $2.0(0.6)$ \\
Nonatretic & $0.4(0.2)$ & $0.6(0.4)$ & $1.0(0.0)$ \\
NA - AGCs & $0.0(0.0)$ & $0.2(0.2)$ & $1.0(0.0)^{\mathrm{a}}$ \\
NA + AGCs & $0.4(0.2)$ & $0.4(0.4)$ & $0.0(0.0)$ \\
Atretic & $2.6(1.1)$ & $7.4(1.6)^{\mathrm{a}, \mathrm{b}}$ & $1.0(0.6)$ \\
LA & $2.0(1.3)$ & $2.0(0.8)$ & $0.3(0.3)$ \\
DA & $0.6(0.4)$ & $4.6(1.5)^{\mathrm{a}, \mathrm{b}}$ & $0.0(0.0)$ \\
HA & $0.0(0.0)$ & $0.6(0.4)$ & $0.7(0.3)$ \\
& & & \\
\hline
\end{tabular}

NA - AGCs: nonatretic follicles without atypical granulosa cells; NA + AGCs: nonatretic follicles with atypical granulosa cells; LA: lightly atretic follicles; DA: definitely atretic follicles; HA: heavily atretic follicles.

${ }^{a}, \mathrm{~b} V$ alues significantly $(P<0.05)$ different from untreated heifers, and heifers at $48 \mathrm{~h}$ after luprostiol treatment, respectively.

treatment compared with that from untreated animals. The largest increase in mean diameter of nonatretic follicles without atypical granulosa cells was observed on the first day after prostaglandin treatment in cows, and at the second day in heifers.

\section{Discussion}

In ovaries of heifers and cows at $48 \mathrm{~h}$ after PG treatment, that is, from I day before oestrus, the largest follicle is nonatretic, lacks atypical granulosa cells and is the only nonatretic follicle present in the class of follicles larger than $6 \mathrm{~mm}$. Quirck et al. (1986) demonstrated that, in prostaglandin-treated heifers, the 
Table 3. The effect of the prostaglandin analogue luprostiol (PG) at $24 \mathrm{~h}$ and $48 \mathrm{~h}$ after injection on the mean number ( \pm SEM) of medium-sized $(3.0-5.9 \mathrm{~mm})$ and large $(\geq 6 \mathrm{~mm})$ ovarian follicles in cows

\begin{tabular}{lrrl}
\hline & \multicolumn{3}{c}{ Cows } \\
\cline { 2 - 4 } Follicles & Untreated & PG 24h & PG 48 h \\
\hline & & & \\
Antral (3-5.9 mm) & $10.2(1.9)$ & $11.4(2.9)$ & $6.0(1.7)$ \\
Nonatretic & $1.6(0.5)$ & $1.6(0.7)$ & $0.0(0.0)$ \\
NA - AGCs & $0.6(0.2)$ & $0.6(0.4)$ & $0.0(0.0)$ \\
NA + AGCs & $1.0(0.4)$ & $1.0(0.4)$ & $0.0(0.0)$ \\
Atretic & $8.6(1.8)$ & $9.8(2.5)$ & $6.0(1.7)$ \\
LA & $2.0(0.6)$ & $4.8(1.0)$ & $2.3(1.3)$ \\
DA & $3.6(0.7)$ & $2.4(1.2)$ & $2.7(0.9)$ \\
HA & $3.0(1.0)$ & $2.6(1.6)$ & $1.0(0.6)$ \\
Antral ( $\geq 6$ mm) & $2.0(0.5)$ & $3.8(1.1)$ & $1.7(0.8)$ \\
Nonatretic & $0.4(0.2)$ & $1.0(0.3)$ & $1.0(0.0)$ \\
NA - AGCs & $0.2(0.2)$ & $0.8(0.2)$ & $1.0(0.0)^{\mathrm{a}}$ \\
NA + AGCs & $0.2(0.2)$ & $0.2(0.2)$ & $0.0(0.0)$ \\
Atretic & $1.6(0.4)$ & $2.8(0.9)$ & $0.7(0.6)$ \\
LA & $0.2(0.2)$ & $0.6(0.6)$ & $0.3(0.3)$ \\
DA & $1.2(0.2)$ & $1.2(0.6)$ & $0.3(0.3)$ \\
HA & $0.2(0.2)$ & $1.0(0.5)$ & $0.0(0.0)$ \\
& & & \\
\hline
\end{tabular}

NA - AGCs: nonatretic follicles without atypical granulosa cells; NA + AGCs: nonatretic follicles with atypical granulosa cells; LA: lightly atretic follicles; DA: definitely atretic follicles; HA: heavily atretic follicles.

${ }^{2} V a l u e ~ s i g n i f i c a n t l y ~(P<0.05)$ different from untreated cows.

Table 4. Mean diameter $(\mathrm{mm} \pm \mathrm{SEM})$ of the largest antral (atretic and nonatretic), the largest atretic, the largest nonatretic (those with and those without atypical granulosa cells; AGCs) and the largest nonatretic follicle without atypical granulosa cells (NA - AGCs) in untreated heifers and cows and in animals at $24 \mathrm{~h}$ and $48 \mathrm{~h}$ after prostaglandin (PG) treatment

\begin{tabular}{lrrrr}
\hline Follicles & Antral & Atretic & Nonatretic & NA-AGCs \\
\hline Heifers & & & & \\
$\quad$ Untreated & $11.8(1.2)$ & $11.8(1.2)$ & $4.8(1.6)$ & $2.6(0.5)$ \\
PG 24 h & $12.1(1.5)$ & $12.1(1.5)$ & $5.5(0.8)$ & $4.4(0.9)$ \\
PG 48 h & $11.3(1.3)$ & $8.6(2.9)$ & $11.3(1.3)$ & $11.3(1.3)$ \\
Cows & & & & \\
Untreated & $13.7(0.7)$ & $13.7(0.7)$ & $5.6(1.4)$ & $3.6(0.7)$ \\
PG 24h & $14.3(1.6)$ & $10.1(1.9)$ & $10.7(2.6)$ & $10.7(2.6)$ \\
PG 48 h & $14.0(1.8)$ & $4.4(1.2)$ & $14.0(1.8)$ & $14.0(1.8)$ \\
\hline
\end{tabular}

largest follicle present at $I$ day before oestrus is the follicle that ovulates. Consequently, in cattle, absence of atypical granulosa cells in the largest nonatretic follicle, present at $48 \mathrm{~h}$ after prostaglandin treatment, can be considered a characteristic for this preovulatory-sized follicle and thus for follicle quality. The presence of atypical granulosa cells as markers for a lower quality follicle is confirmed by the observation that the proportion of follicles with large numbers of atypical granulosa cells is higher in the category of definitely atretic follicles than in nonatretic follicles. This finding clearly points to an association of atypical granulosa cells with the process of follicular atresia and corresponds to previous observations, showing the coincidence of the presence of atypical granulosa cells with the occurrence of degenerative changes in the cytoplasm of nearby granulosa cells (van den Hurk et al., 1992). Because of the presence of atretic granulosa cells, we hypothesize that a great part of the population of nonatretic follicles, known as nonatretic according to current histological criteria, is of suboptimal quality. Cells that are histologically similar to atypical granulosa cells have been demonstrated in cows (Lobel and Levy, 1968; Priedkalns et al., 1968; McKenzie and Kenney, 1973; Monniaux et al., 1984) and in various other mammals (Clark, 1923; Ingram, 1962; Horowitz, 1967; Koering, 1969; Brand and de Jong, 1973), but only in follicles at an advanced stage of atresia.

Administration of prostaglandin during the mid-luteal stage of the oestrous cycle initially leads to a sharp increase in the number of definitely atretic follicles larger than $6 \mathrm{~mm}$ in heifers, but not in cows. In the present study, contrary to body weights, injected doses of luprostiol were the same for heifers and cows. The atresia promoting effect of prostaglandin may thus be due to the relatively high doses administered to heifers. An increase of follicle atresia after prostaglandin treatment of heifers was also observed by Cheremisinov et al. (1986), when a relatively high dose of cloprostenol was injected. In sheep, the appearance of a widespread increase in atresia in follicles $>\mathrm{Imm}$ after prostaglandin (cloprostenol) injection, is accompanied by the emergence of a preovulatory follicle (McNatty et al., 1982). In all heifers at $24 \mathrm{~h}$ after injection of prostaglandin increased numbers of atretic follicles $\geq 6 \mathrm{~mm}$ are generally accompanied by the presence of one medium-sized nonatretic follicle without atypical granulosa cells. This nonatretic follicle is probably the selected preovulatory follicle, as $48 \mathrm{~h}$ after prostaglandin treatment, all heifers have only one large preovulatory-sized follicle, in which atypical granulosa cells are absent.

Development of relatively large numbers of large follicles in heifers at $24 \mathrm{~h}$ after luprostiol treatment may be attributed to an indirect effect of the injected compound, as injection of prostaglandin evoked reduced progesterone concentrations that resulted in enhanced gonadotrophin concentrations in the circulation of farm animals, including cattle (Hansel and Convey, 1983; Jöchle et al., 1987). In consequence, a number of follicles are rapidly recruited from the pool of medium-sized follicles, from which one is chosen to ovulate, and the remainder become atretic. Ko et al. (1991) showed that, in cows, the selected preovulatory follicle caused regression of its subordinate follicles. This dominant follicle may influence the development of other follicles, either directly by secretion of an unknown paracrine substance, or indirectly by inhibition of the FSH support to follicles, via negative feedback action of oestradiol and inhibin produced (Driancourt, 1991). Follicular regression is generally accompanied by follicular shrinkage (Rajakoski, 1960; Ingram, 1962; Marion et al., 1968; Byskov, 1978), and in heifers may come to $4-7 \mathrm{~mm}$ per day after prostaglandin treatment, if diameters are determined by measuring dissected follicles (Quirck et al. 1987). This rapid decrease in the size of nonovulatory follicles explains the strong decline in the number of large atretic follicles in heifers between 24 and $48 \mathrm{~h}$ after prostaglandin treatment. 
In cows, the preovulatory-sized follicle appears to grow extremely quickly after injection of prostaglandin. The increase in diameter of this follicle amounts to $6.5 \mathrm{~mm}$ and over $8 \mathrm{~mm}$ for heifers and cows, respectively. If it is assumed that only a nonatretic follicle without atypical granulosa cells becomes a preovulatory-sized follicle, the mean diameters of the largest follicles of this type have to be compared. In that case, growth of the preovulatory-sized follicle within $48 \mathrm{~h}$ after PG treatment is almost 9 and over $10 \mathrm{~mm}$ for heifers and cows, respectively. These data support previous data of Dieleman et al. (1986), who established, by rectal palpation of a few cows, that a preovulatory follicle may grow from less than $8 \mathrm{~mm}$ to ovulatory size $(18-20 \mathrm{~mm})$ in about 2.5 days before the $\mathrm{LH}$ surge, thus during the period of luteal regression. The data are also in agreement with findings of Matton et al. (1981), who showed that destruction of all follicles larger than $5 \mathrm{~mm}$ at day 18 did not delay oestrus, indicating that follicles were capable of growing from $<5 \mathrm{~mm}$ to ovulatory size within several days. On the basis of ultrasonic measurements, Quirck et al. (1987) observed a mean increase of $4-6 \mathrm{~mm}$ in diameter of preovulatory follicles in prostaglandin-treated heifers during the 3 days before oestrus. In their studies, however, diameters of follicles determined by ultrasonography were consistently 2-3 mm smaller than diameters of dissected follicles. In cows, the greatest growth of nonatretic follicles was observed at the first day after prostaglandin treatment, whereas, in heifers, the same phenomenon was observed one day later. In addition, compared with heifers, cows show a greater decrease in the size of atretic follicles at the second day after progesterone treatment. These findings suggest that luteolysis proceeds at a slower rate in heifers than in cows, and this confirms the observations of Dieleman et al. (1986).

In conclusion, in cows, atypical granulosa cells can be considered as markers for a lower quality follicle, based on their absence in preovulatory-sized follicles and their presence in large numbers in a high proportion of definitely atretic follicles. After prostaglandin-induced luteolysis, the mean number of medium-sized and large nonatretic follicles with atypical granulosa cells and those of atretic follicles in heifers and cows were not different from untreated animals. However, in heifers, contrary to cows, the development of a preovulatory-sized follicle is initially accompanied by an increase in the number of large definitely atretic follicles. Within 2 days after prostaglandin treatment, the mean diameter of a preovulatory-sized follicle increases almost 9 and over $10 \mathrm{~mm}$ in heifers and cows, respectively.

The authors thank M. M. Bevers for critically reviewing the manuscript, J. van de Broek for statistical advice and R. V. Leito for preparing the figures.

\section{References}

Brand A and De Jong WHR (1973) Qualitative and quantitative micromorphological investigations of the tertiary follicle population during the oestrous cycle in sheep Joumal of Reproduction and Fertility 33 431-439

Byskov AG (1978) Follicular atresia. In The Vertebrate Ovary pp 533-562 Ed. RE Jones. Plenum Press, New York

Cheremisinov GA, Eremin SP and Karamyshev VA (1986) Investigation of the optimal dose of prostaglandin $\mathrm{F} 2$ alpha for regulation of sexual function in heifers Animal Breeding Abstracts 054-01567
Choudary JB, Gier HT and Marion GB (1968) Cyclic changes in bovine vesicular follicles Joumal of Animal Science 27 468-471

Clark EB (1923) Observations on the ova and ovaries of the guinea pig, Cavia cobaya Anatomical Record 25 313-331

Dieleman SJ and Bevers MM (1987) Effects of monoclonal antibody against PMSG administered shortly after the preovulatory LH surge on time and number of ovulations in PMSG/PG-treated cows Joumal of Reproduction and Fertility 81 533-542

Dieleman SJ, Kruip ThAM, Fontijne P, De Jong WHR and Van Der Weyden GC (1983) Changes in oestradiol, progesterone and testosterone concentrations in follicular fluid and in the micromorphology of preovulatory bovine follicles relative to the peak of luteinizing hormone Journal of Endocrinology 97 31-42

Dieleman SJ, Bevers MM, Tol HTM van and Willemse AH (1986) Peripheral plasma concentrations of oestradiol, progesterone, cortisol, $\mathrm{LH}$ and prolactin during the oestrous cycle in the cow, with emphasis on the peri-oestrous period Animal Reproduction Science 10 275-292

Driancourt MA (1991) Follicular dynamics in sheep and cattle Theriogenology 35 55-79

Gallo GF, Algire JE, Srikandakumar A and Downey BR (1992) Effects of prostaglandin $F 2 \alpha$ analogue on the ovulatory response of superovulated heifers Animal Reproduction Science 27 83-90

Hansel W and Convey EM (1983) Physiology of the estrous cycle Journal of Animal Science 57 Supplement 2 404-423

Horowitz M (1967) The anovular corpus luteum in the golden hamster (Mesocricetus auratus Waterhouse) and comparison with the normal corpus luteum and follicle of atresia Acta Anatomica 66 199-225

Hurk R van den and Dijkstra GJ (1992) An immunohistochemical study of bovine antral follicles, with special attention to non-atretic follicles with and without atypical granulosa cells Veterinary Quarterly 14 148-151

Hurk R van den, Spek ER, Dijkstra G, Vorstenbosch CJAHV van, Hulshof SCJ and Dieleman SJ (1992) Effects of pregnant mares' serum gonadotrophin on antral follicles in heifers: a micromorphological study with special reference to atypical granulosa cells Journal of Reproduction and Fertility 95 903-913

Ingram DL (1962) Atresia. In The Ovary Vol 1 pp 247-273 Ed. S. Zuckerman. Academic Press, New York

Ireland JJ and Roche JF (1982) Development of antral follicles in cattle after prostaglandin-induced luteolysis: changes in serum hormones, steroids in follicular fluid, and gonadotropin receptors Endocrinology 111 2077-2086

Jöchle W, Irvine CHG, Alexander SL and Newby TJ (1987) Release of LH, FSH and GnRH into pituitary venous blood in mares treated with a PGF analogue, luprostiol, during the transition period Journal of Reproduction and Fertility Supplement 35 26I-267

Ko JCH, Kastelic JP, DelCampo MR and Ginther OJ (1991) Effects of a dominant follicle on ovarian follicular dynamics during the oestrous cycle in heifers Journal of Reproduction and Fertility 91 511-519

Koering MJ (1969) Cyclic changes in ovarian morphology during the menstrual cycle in Macaca mulata American Journal of Anatomy 126 73-101

Kruip ThAM and Dieleman SJ (1982) Macroscopic classification of bovine follicles and its validation by micromorphological and steroid biochemical procedures Reproduction, Nutrition and Development 22 465-473

Lobel BL and Levy E (1968) Growth and maturation of follicles: enzymic correlates of development, secretory function and regression of follicles and corpora lutea in the bovine ovary Acta Endocrinologica (Supplement) 132 $7-63$

Louis TM, Hafs HD and Stellflug JN (1975) Control of ovulation, fertility and endocrine response after prostaglandin F2 $\alpha$ in cattle Annales de Biologie Animale, Biochimie ef Biophysique 15 407-417

McKenzie BE and Kenney RM (1973) Histologic features of ovarian follicles of gonadotropin-injected heifers American Joumal of Veterinary Science 34 1033-1040

McNatty KP, Gibb M, Dobson C, Ball K, Coster J, Heath D and Thurley DC (1982) Preovulatory follicular development in sheep treated with PMSG and/or prostaglandin Journal of Reproduction and Fertility $65111-123$

Marion GB, Gier HT and Choudary JB (1968) Micro morphology of the bovine follicular system Journal of Animal Science 27 451-465

Matton P, Adelakoun V, Couture Y and Dufour Jf (1981) Growth and replacement of the bovine ovarian follicles during the estrous cycle Journal of Animal Science 52 813-820

Monniaux D, Mariana JC and Gibson WR (1984) Action of PMSG on follicular populations in the heifer Journal of Reproduction and Fertility 70 243-253

Phillipo M and Rowson LEA (1975) Prostaglandins and superovulation in the bovine Annales de Biologie Animale, Biochimie et Biophysique 15 233-240 
Priedkalns J, Weber AF and Zemjanis R (1968) Qualitative and quantitative morphological studies of the cells of the membrana granulosa, theca interna and corpus luteum of the bovine ovary Zeitschrift für Zellforschung und mikroskopischer Anatomie 85 501-520

Quirck SM, Hickley GJ and Fortune JE (1986) Growth and regression of ovarian follicles during the follicular phase of the oestrous cycle in heifers undergoing spontaneous and PGF-2a-induced luteolysis Journal of Reproduction and Fertility 77 211-219

Rajakoski E (1960) The ovarian follicular system in sexually mature heifers with special reference to seasonal, cyclical, and left-right variations Acta Endocrinologica Supplementum 52 6-68
Siegel S (1959) Nonparametric Statistics for the Behavioural Sciences. McGraw-Hill Book Company, New York

Walpole PJ (1975) Characteristics of prostaglandins Annales de Biologie Animale, Biochimie et Biophysique 15 389-406

Wright PJ and Malmo J (1992) Pharmacologic manipulation of fertility Veterinary Clinics of North America: Food Animal Practice 8 57-89 